\title{
Induction of arginosuccinate synthetase (ASS) expression affects the antiproliferative activity of arginine deiminase (ADI) in melanoma cells
}

\author{
ANTONELLA MANCA $^{1}$, MARIA CRISTINA SINI ${ }^{1}$, FRANCESCO IZZO $^{2}$, PAOLO A. ASCIERTO $^{2}$, \\ FABIANA TATANGELO ${ }^{2}$, GERARDO BOTTI ${ }^{2}$, GIUSY GENTILCORE ${ }^{2}$, MARILENA CAPONE ${ }^{2}$, \\ NICOLA MOZZILLO ${ }^{2}$, CARLA ROZZO $^{1}$, ANTONIO COSSU $^{3}$, FRANCESCO TANDA $^{4}$ and GIUSEPPE PALMIERI ${ }^{1}$ \\ ${ }^{1}$ Institute of Biomolecular Chemistry (ICB), National Research Council (CNR), Traversa La Crucca, 07100 Sassari; \\ ${ }^{2}$ National Cancer Institute-Fondazione Pascale, Via Mariano Semmola, 80131 Naples; ${ }^{3}$ Pathology Service, Hospital-University \\ Health Unit (AOU), Via Matteotti 58; ${ }^{4}$ Institute of Pathology, University of Sassari, Via Matteotti 48, 07100 Sassari, Italy
}

Received January 7, 2011; Accepted February 11, 2011

DOI: $10.3892 / o r .2011 .1220$

\begin{abstract}
Arginine deiminase (ADI), an arginine-degrading enzyme, has been used in the treatment of tumours sensitive to arginine deprivation, such as malignant melanoma (MM) and hepatocellular carcinoma (HCC). Endogenous production of arginine is mainly dependent on activity of ornithine transcarbamylase (OTC) and argininosuccinate synthetase (ASS) enzymes. We evaluated the effect of ADI treatment on OTC and ASS expression in a series of melanoma cell lines. Twenty-five primary melanoma cell lines and normal fibroblasts as controls underwent cell proliferation assays and Western blot analyses in the presence or absence of ADI. Tissue sections from primary MMs $(\mathrm{N}=20)$ and HCCs $(\mathrm{N}=20)$ were investigated by immunohistochemistry for ASS expression. Overall, 21/25 (84\%) MM cell lines presented a cell growth inhibition by ADI treatment; none of them presented constitutive detectable levels of the ASS protein. However, 7/21 (33\%) ADI-sensitive melanoma cell lines presented markedly increased expression levels of the ASS protein following ADI treatment, with a significantly higher $\mathrm{IC}_{50}$ median value. Growth was not inhibited and the $\mathrm{IC}_{50}$ was not reached among the remaining 4/25 (16\%) MM cell lines; all of them showed constitutive ASS expression. The OTC protein was found expressed in all melanoma cell lines before and after the ADI treatment. Lack of ASS immunostaining was observed in all analyzed in vivo specimens. Our findings suggest that response to ADI treatment in melanoma is significantly correlated with the ability of cells to express ASS either constitutively at basal
\end{abstract}

Correspondence to: Dr Giuseppe Palmieri, Institute of Biomolecular Chemistry (ICB)-National Research Council (CNR), Traversa La Crucca 3 - Baldinca Li Punti, 07100 Sassari (SS), Italy

E-mail: gpalmieri@yahoo.com

Key words: arginine deiminase, argininosuccinate synthetase, expression analysis, malignant melanoma, in vitro proliferation test level (inducing drug resistance) or after the treatment (reducing sensitivity to ADI).

\section{Introduction}

Arginine is involved in the synthesis of a wide range of proteins, production of creatine and nitric oxide, and several metabolic pathways (1). In addition to dietary intake and muscle degradation, a fundamental source of arginine is its endogenous synthesis in somatic cells ubiquitously (this is the reason why arginin is considered as a semi-essential amino acid in adult humans) $(1,2)$. In particular, the ornithine transcarbamylase (OTC) catalyzes the synthesis of citrulline, which, in turn, is converted to arginine by argininosuccinate synthetase (ASS) and argininosuccinate lyase (ASL) $(3,4)$. However, the reactions induced by OTC and ASS represent the rate-limiting step in the recycling of citrulline to arginine; among them, ASS is considered as a key enzyme in the synthesis of arginine at somatic levels in humans $(3,4)$.

Malignant melanoma (MM) and hepatocellular carcinoma (HCC) have been demonstrated to be dependent on exogenous arginine for growth because of the lack of capacity of their neoplastic cells to synthesize arginine $(5,6)$. Depletion of arginine could be achieved by inducing the arginase, which converts arginine to ornithine and urea in mammals $(7,8)$; another enzyme able to deplete the arginine is represented by the arginine deiminase (ADI), which catalyzes, in microbes but not in mammals, the hydrolysis of arginine into citrulline and ammonia (9-11). Recently, the use of ADI conjugated to polyethylene glycol (ADI-PEG) has been introduced into the therapy of both MM and HCC, aimed to achieve an antiproliferative effect through depletion of arginine in cancer cells of such patients $(6,12,13)$. As previously demonstrated by our group, the ADI-PEG treatment of patients with unresectable HCC or advanced MM indeed resulted in measurable antitumour response $(14,15)$, showing also to be effective in lowering plasma concentration of arginine as well as improving liver function in HCC patients with chronic hepatitis $\mathrm{C}$ virus infection (16). 
Finally, resistance to ADI treatment in several cancer cell lines seems to correlate with the rate of activity of the enzymes (mainly, ASS) involved in converting arginine from citrulline (17). In other words, the antitumour activity of ADI-mediated arginine depletion may be strongly dependent on the efficiency by which ASS can regenerate arginine from citrulline at cellular level (probably, the impact of this mechanism on effectiveness of the ADI-PEG therapy is much higher than the auxotrophic requirement of arginine) $(6,11,17)$. In the present study, we evaluated the effect of ADI treatment on OTC and ASS expression in a representative series of primary melanoma cell lines, by evaluating the capability of the ADI antiproliferative activity to induce the ASS expression.

\section{Materials and methods}

Cell lines and culture conditions. Melanoma cell lines were obtained from the Institute Dermopatico dell' Immacolata (IDI) of Rome and from the National Cancer Institute of Naples. They were established as primary short-term cell cultures starting from tumour samples of donors patients with documented diagnosis of melanoma, after obtaining their informed consent, as previously reported (18). Short-term cultures of normal human fibroblasts from healthy donors named BJ (CRL-2522) were purchased from the American Type Culture Collection (ATCC) and served as controls. All cells were grown either in Dulbecco's minimal essential (DMEM; Sigma, St. Louis, MO, USA) or in RPMI (Invitrogen, Carlsbad, CA, USA) media, supplemented with $10 \%$ FBS and penicillin-streptomycin (100 IU $/ 50 \mu \mathrm{g} / \mathrm{ml})$, as previously described $(19,20)$.

Cell proliferation assay. Cells were plated in triplicate in 96-well plates, at a density of $3-5 \times 10^{3}$ per well, in complete medium; after $24 \mathrm{~h}$, medium was replaced with fresh medium only (controls) or medium containing different concentrations of ADI (0-2.5 mU/ml). The percentage of cell proliferation was estimated on day 6 by the colorimetric assay as in Kueng et al (21), modified as follows: cells were fixed for $20 \mathrm{~min}$ at room temperature with $4 \%$ paraformaldehyde (PFA), stained with $0.1 \%$ crystal violet in $20 \%$ methanol for 20 min, washed in PBS, solubilized with $10 \%$ acetic acid and read at $595 \mathrm{~nm}$ in a microplate reader (SpectraFluor Plus, Tecan, Austria).

Western blot analysis. Cells were plated in two T75 tissue culture flasks $\left(6 \times 10^{5}\right.$ cells/flask) in complete medium; at days 1, 3 and 5, cells in one flask were treated with medium containing $\mathrm{ADI}$ at a concentration required for $50 \%$ growth inhibition $\left(\mathrm{IC}_{50}\right)$, whereas those in the second flasks received the simple replacement of medium (control). At day 6, cells were harvested, using cell-scraper and cold PBS, and then lysed with Cell Extraction Buffer (BioSource International, Camarillo, CA, USA) plus protease inhibitor cocktail (Sigma). For each cell lysate, protein concentration was determined by the QuantiPro BCA Assay Kit (Sigma). Proteins (50 $\mu \mathrm{g}$ per lane) were electrophoresed on sodium dodecyl sulphate (SDS) $12 \%$ polyacrylamide gels and transferred by electroblotting to nitrocellulose membranes (GE Healthcare, Little Chalfont, UK). For immunoblotting, membranes were then incubated with monoclonal antibodies against ASS (1:2500; BD, Franklin Lakes, NJ, USA) and OTC (1:1000, Santa Cruz Biotech, Santa Cruz, CA, USA). Detection was achieved by HRP-conjugated anti-mouse (1:10.000; Chemicon, Billerica, MA, USA) for anti-ASS antibody or HRP-conjugated antirabbit (Santa Cruz Biotech, 1:10.000) for anti-OTC antibody, and enhanced chemiluminescent kit (ECL Advance, GE Healthcare), according to the manufacturer's instructions; expression was normalized to internal controls, using a mouse antibody against GAPDH (Santa Cruz Biotech).

Immunohistochemistry (IHC). For IHC analysis, 4- $\mu \mathrm{m}$ sections from formalin-fixed, paraffin-embedded tissues from 10 primary melanomas and 20 hepatocellular carcinomas were immunostained using anti-ASS monoclonal antibody (BD).

Protocol for immunostaining was previously described by our group (22). Briefly, tissue sections were deparaffinized in xylol and rehydrated in graded alcohols. Endogenous peroxidase activity was blocked with $3 \%$ hydrogen peroxide solution. After incubation with the monoclonal antibody anti-ASS (dilution, 1:50), the bound antibody was visualized using a biotinylated secondary antibody, avidin-biotin peroxidase complex (Biogenex-Menarini), and the 3-amino-9-ethylcarbazole (DakoCytomation). Nuclear counterstaining was performed with hematoxylin (DakoCytomation). Slides were viewed using a BX61 Olympus Microscope supplied with DP 50 camera and Viewfinder Lite 1.0 Version (Pixera Corporation) image analysis system. Labelling intensity was expressed as percentage of stained area; subcellular staining was evaluated with a x10, x20 and x40 objectives, by two independent observers.

\section{Results}

Growth inhibition in ADI-treated melanoma cell lines. To assess the antiproliferative activity of ADI in melanoma, growth assays were performed on $25 \mathrm{MM}$ cell lines established as short-term cultures from primary and metastatic tumours of melanoma patients, using five different concentrations of the drug: $0.5,1.0,1.5,2.0$ and $2.5 \mathrm{mU} / \mathrm{ml}$ (in addition to the negative control represented by the medium alone). A significant suppression in cell proliferation was observed in 21/25 (84\%) MM cell lines treated with ADI in a dose-dependent manner; the median $\mathrm{IC}_{50}$ value in this large subset was $1.3 \mathrm{mU} / \mathrm{ml}$ (range, 0.4-2.0). Fig. 1 shows the cell growth inhibition of all ADI-sensitive MM cell lines, after five days of treatment with increasing concentrations of ADI. In the remaining $4(16 \%)$ melanoma cell lines, growth was not inhibited and the $\mathrm{IC}_{50}$ was not reached, even after a remarkable increase of the ADI concentrations into the medium (up to $100 \mathrm{mU} / \mathrm{ml}$ ) (Fig. 2). As expected, proliferation of the fibroblasts as control was not inhibited by the ADI treatment (Fig. 2). A summary of all the $\mathrm{IC}_{50}$ values obtained in our series of $\mathrm{MM}$ cell lines is reported in Table I.

Expression of ASS and OTC proteins in ADI-treated melanoma cell lines. Expression analysis revealed that none of the 21 ADI-responsive cell lines presented detectable levels of the ASS protein before the ADI treatment; conversely, the 
A

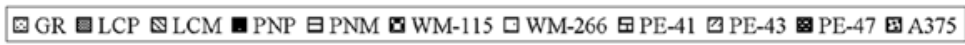

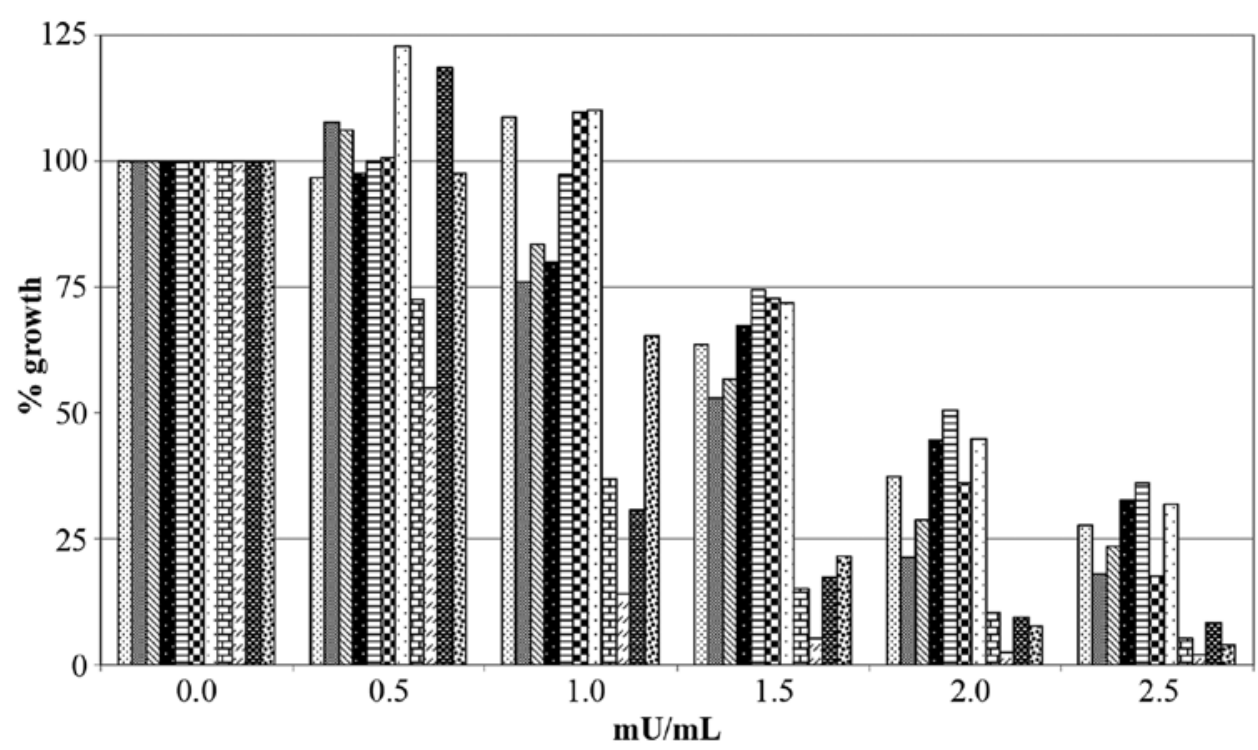

B

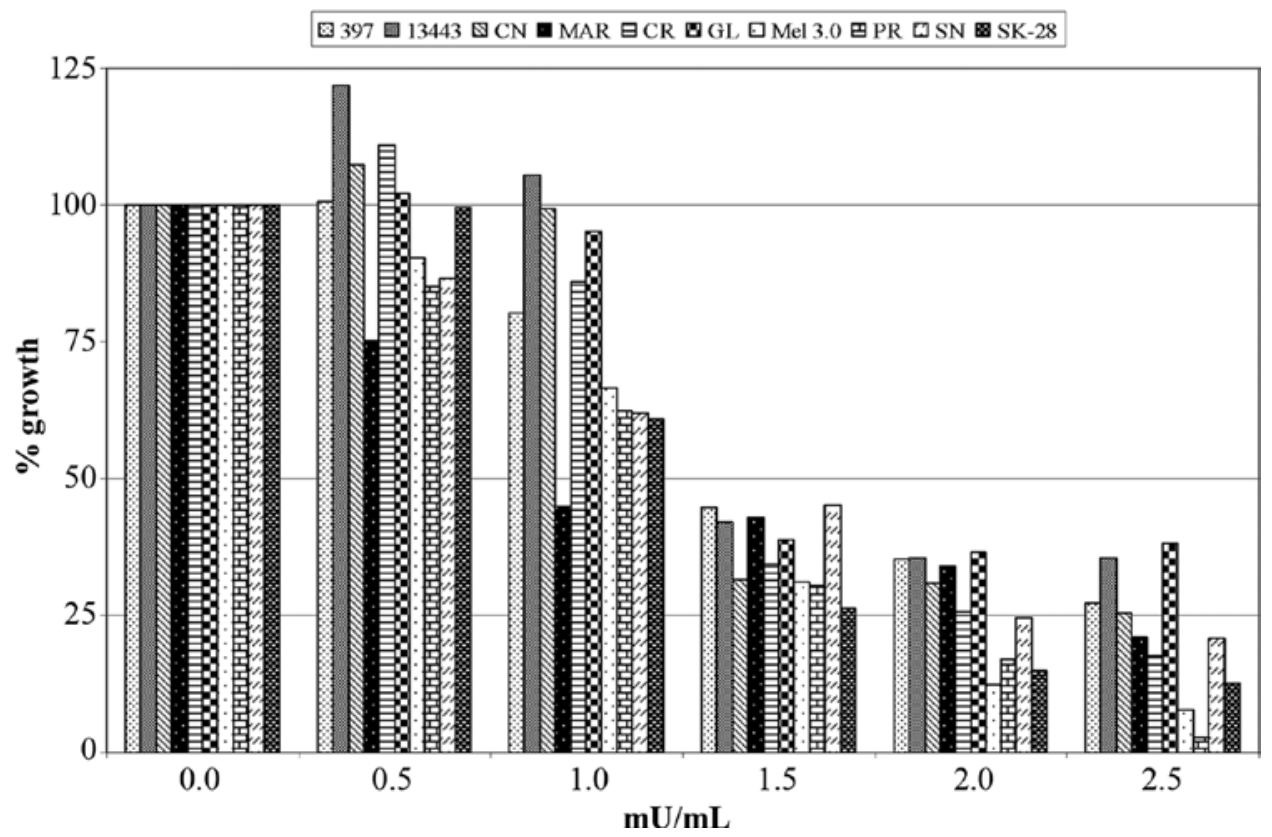

Figure 1. Growth diagrams of ADI-sensitive melanoma cell lines. Human MM cell lines were cultured in presence of RPMI medium alone (negative control) and increasing concentration of ADI for 6 days. Results are expressed as percent of cell growth and represent the average of triplicate cultures performed twice. (A), paired cell lines derived from primary melanomas and MM metastases of the same patients are included.

four melanoma cell lines and the normal fibroblasts, which did not reach an $\mathrm{IC}_{50}$ value, showed a constitutive ASS expression in both treated and untreated cells (Table I). In Fig. 3, representative examples of the ASS expression as detected by Western blot hybridization are shown. After treatment with $\mathrm{ADI}$ at concentrations corresponding to the $\mathrm{IC}_{50}$ values, $7 / 21(33 \%)$ melanoma cell lines presented a remarkable increase of the expression levels of the ASS protein; six of them were from paired primary and secondary lesions of three patients (Table I). In this subset, the median value of
$\mathrm{IC}_{50}$ was $1.8 \mathrm{mU} / \mathrm{ml}$ (range, 1.3-2.0) and the average of $\mathrm{IC}_{50}$ values was $1.82 \mathrm{mU} / \mathrm{ml}$ (Table I). The remaining 14/21 (67\%) ADI-responsive cell lines maintained a negative ASS expression after treatment; among them, three cell lines were from paired secondary lesions of the same patient (Table I). In this subset, median value of $\mathrm{IC}_{50}$ was $1.2 \mathrm{mU} / \mathrm{ml}$ (range, 0.4-1.4) and the average of $\mathrm{IC}_{50}$ values was $1.12 \mathrm{mU} / \mathrm{ml}$ (Table I). Considering the relationship between the $\mathrm{IC}_{50}$ values and the ASS expression status before and after the treatment with ADI (negative/negative, negative/positive and positive/positive), the 
A

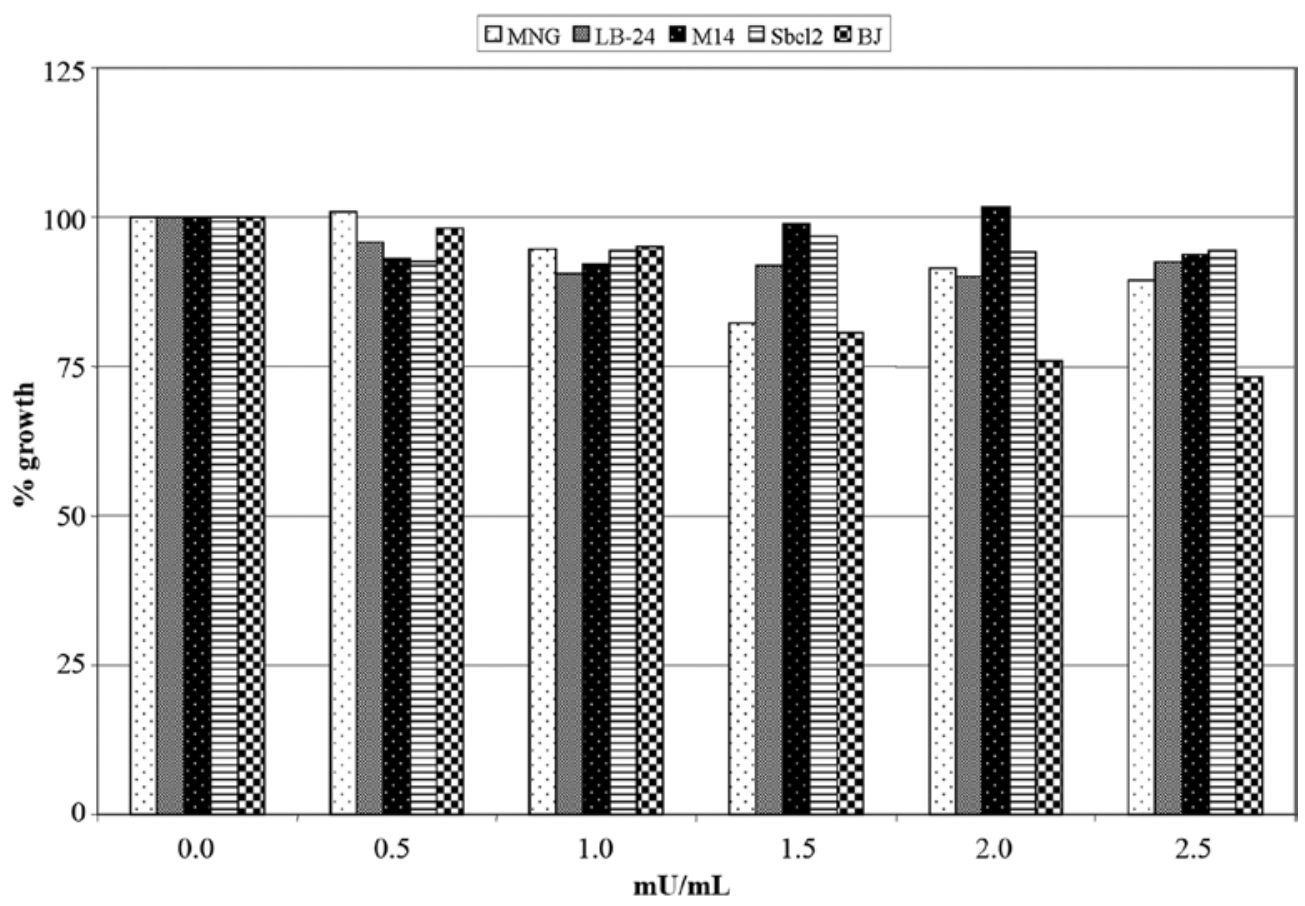

B

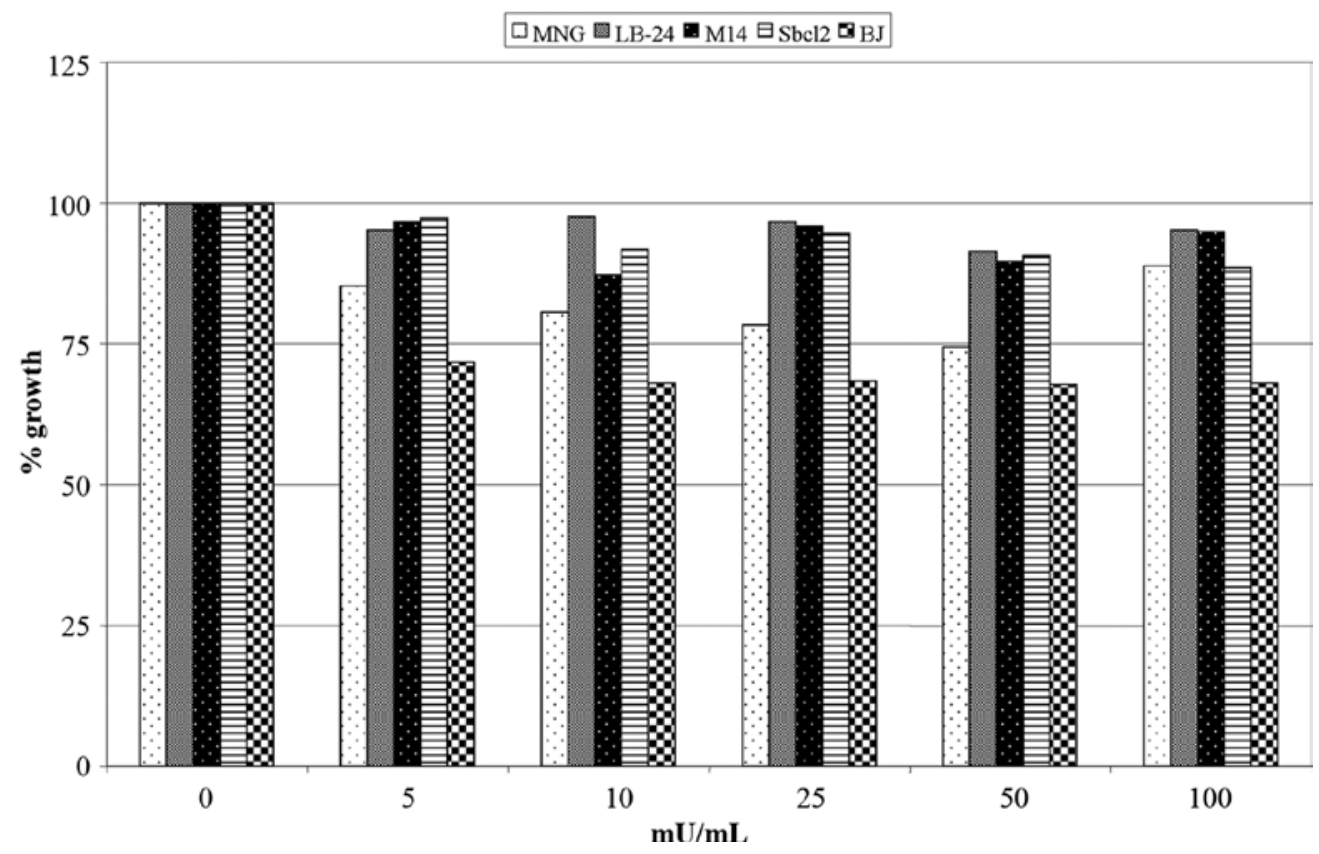

Figure 2. Growth diagrams of ADI-resistant melanoma cell lines. Human MM cell lines were cultured in presence of RPMI medium alone (negative control) and increasing concentrations, (A), as for Fig. 1; (B), up to $100 \mathrm{mU} / \mathrm{ml}$ of ADI for 6 days. Results are expressed as percent of cell growth and represent the average of triplicate cultures performed twice.

most drug-sensitive cell lines were those with no detectable expression of ASS in any phase of the treatment; conversely, the MM cell lines with induction of the ASS expression presented a reduced degree of sensitivity to ADI. As expected, the cell lines with constitutive ASS expression, which was not modified by the treatment, were clearly resistant to ADI, even at higher concentrations of the drug. Statistical analysis performed using the $\mathrm{IC}_{50}$ values and the ASS expression status as continuous variables indicated that the linear trend of such an association was significant ( $\mathrm{p}=0.023$; not shown). Interestingly, the ADI-sensitive cell lines derived from paired primary and metastatic lesions of the same MM patients presented identical responses for ASS expression (presence vs. absence of ASS induction after treatment) as well as similar $\mathrm{IC}_{50}$ values when treated with ADI (Table I). Finally, no association was inferred considering the anatomical site of melanoma tissues from which MM cell lines were established (data not shown). 
Table I. Comparison between $\mathrm{IC}_{50}$ and ASS expression, before and after ADI treatment.

\begin{tabular}{|c|c|c|c|c|c|}
\hline \multicolumn{2}{|c|}{ Cell line } & \multirow{2}{*}{$\begin{array}{c}\text { Origin } \\
\text { Primary MM }\end{array}$} & \multirow{2}{*}{$\frac{\mathrm{IC}_{50} \mathrm{mU} / \mathrm{ml}}{1,80}$} & \multirow{2}{*}{$\begin{array}{c}\text { ASS untreated } \\
-\end{array}$} & \multirow{2}{*}{$\begin{array}{c}\text { ASS treated } \\
+\end{array}$} \\
\hline 01 & GR-Mel & & & & \\
\hline $02 \mathbf{a}$ & LCP-Mel & Primary MM & $\mathbf{1 , 6 0}$ & - & + \\
\hline $\mathbf{0 2 b}$ & LCM-Mel & MM lymph node & 1,65 & - & + \\
\hline $03 \mathbf{a}$ & PNP-Mel & Primary MM & 1,95 & - & + \\
\hline $\mathbf{0 3 b}$ & PNM-Mel & MM lymph node & 2,00 & - & + \\
\hline $04 a$ & WM-115 & Primary MM & 1,80 & - & + \\
\hline 04b & WM-266 & Skin nodule & 1,95 & - & + \\
\hline $05 \mathbf{a}$ & PE-Mel-41 & Skin nodule & $\mathbf{0 , 8 0}$ & - & - \\
\hline $\mathbf{0 5 b}$ & PE-Mel-43 & Lung nodule & $\mathbf{0 , 4 0}$ & - & - \\
\hline $05 \mathrm{c}$ & PE-Mel-47 & Skin nodule & 0,65 & - & - \\
\hline 06 & A375 & Unknown & 1,20 & - & - \\
\hline 07 & 397-Mel & Skin nodule & 1,40 & - & - \\
\hline 08 & 13443-Mel & MM lymph node & 1,40 & - & - \\
\hline 09 & CN-Mel & MM lymph node & 1,35 & - & - \\
\hline 10 & MAR-Mel & MM lymph node & 0,90 & - & - \\
\hline 11 & CR-Mel & MM lymph node & 1,30 & - & - \\
\hline 12 & GL-Mel & MM lymph node & 1,40 & - & - \\
\hline 13 & Mel 3.0 & Unknown & 1,20 & - & - \\
\hline 14 & PR-Mel & Skin nodule & 1,20 & - & - \\
\hline 15 & SN-Mel & Skin nodule & 1,35 & - & - \\
\hline 16 & SK-Mel-28 & Unknown & 1,15 & - & - \\
\hline 17 & MNG-Mel & Primary MM & Not reached & + & + \\
\hline 18 & LB-24-Mel & Skin nodule & Not reached & + & + \\
\hline 19 & M14-RECI & Skin nodule & Not reached & + & + \\
\hline 20 & Sbcl2 & Primary MM & Not reached & + & + \\
\hline 21 & $\mathrm{BJ}$ & Fibroblasts & Not reached & + & + \\
\hline
\end{tabular}

Cell lines from paired primary and metastatic MM lesion of the same patients appear in bold.

Since OTC activity has been demonstrated to affect the sensitivity to ADI treatment, the cell lysates from the same series of MM cells were also analyzed for OTC expression by Western blot hybridization. A constitutive expression of the OTC protein was found in all 25 melanoma cell lines; no change in OTC expression was observed after the ADI treatment (Fig. 3). Therefore, OTC did not play any role in determining the responsiveness to ADI treatment in our series.

Immunohistochemical analysis of in vivo tumour tissue. To evaluate the ASS expression among in vivo tumour tissues of MM patients from our population (in other words, patients with the same geographical origin of those from whom cell lines were derived), immunohistochemistry was carried out with anti-ASS antibody on sections from the archival tissues of 20 primary melanomas. Moreover, 20 primary hepatocellular carcinomas were included into the IHC analysis, since this tumour is the other main malignancy tightly depending on endogenous ASS activity. A negative immunostaining for ASS protein expression was observed in all analyzed tissues.
In Fig. 4, representative IHC results for MM and HCC cases are provided (including the analysis of a normal kidney tissue section as positive control).

\section{Discussion}

The recent introduction of novel anticancer molecules into the clinical practice for the treatment of advanced melanoma [i.e., new drugs targeting signal-transduction pathways or achieving a CTLA-4 blockade $(23,24)]$ further supports the idea that is time for a more appropriate selection of patients to be addressed to the various innovative therapies. Nevertheless, a better clarification of any cause-effect relationship between the new antitumour drugs and their molecular targets will improve the characterization of the subsets of patients who would be expected to be more or less likely to respond to such specific therapeutic interventions.

Recently, a reasonable antitumour activity has been reported by our group for a novel arginine-degrading enzyme-based drug, pegylated arginine deiminase (ADI-PEG), as a treatment 


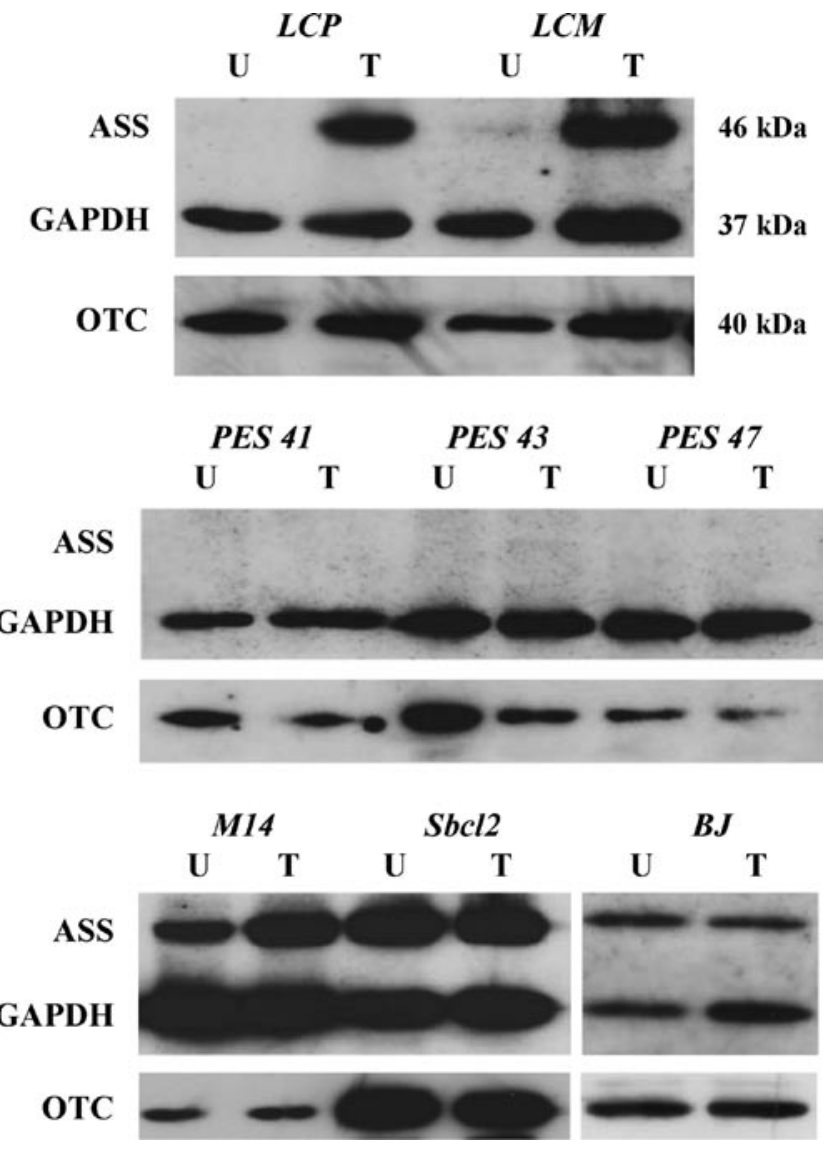

Figure 3. Representative Western blot analysis for ASS and OTC expression in MM cell lines. U, untreated; T, treated.

for melanoma and hepatocellular carcinoma (both tumours are auxotrophic for arginine) $(14,15,25)$. Since the production of endogenous arginine is mainly the result of sequential actions of intracellular OTC and ASS enzymes, an inability to express either enzyme would be expected to result in arginine auxotrophy and sensitivity to ADI-induced arginine deprivation $(3,5,26)$. In this study, we further examined the relationship between the intracellular expression levels of the ASS and OTC proteins and the ADI treatment in a representative series of primary melanoma cell lines $(n=25$; most of them were established as primary short-term cell cultures from tumour samples of donors patients).

A limited fraction $(4 / 25 ; 16 \%)$ of MM cell lines presented high levels of constitutive ASS expression; as expected, no growth inhibition was achieved when treatment with ADI was performed in such a subset. On the other hand, vast majority $(21 / 25 ; 84 \%)$ of MM cell lines from our series did not produce detectable amount of constitutive ASS protein and were responsive to ADI-driven inhibition of proliferation. However, one third $(7 / 21 ; 33 \%)$ of these ADI-sensitive cells presented an induction of the ASS expression after the drug treatment; in this group, the $\mathrm{IC}_{50}$ was obtained using higher concentrations of ADI (Table I). Our findings seem to provide further details on the relationship between cell growth and ADI treatment. Consistently with previous reports (6-7,27-29), lack of expression of ASS markedly predicts sensitivity to ADI treatment; in other words, ADI only inhibits the growth of ASS-deficient cancer cells. As a confirmation of this, all cells presenting
A

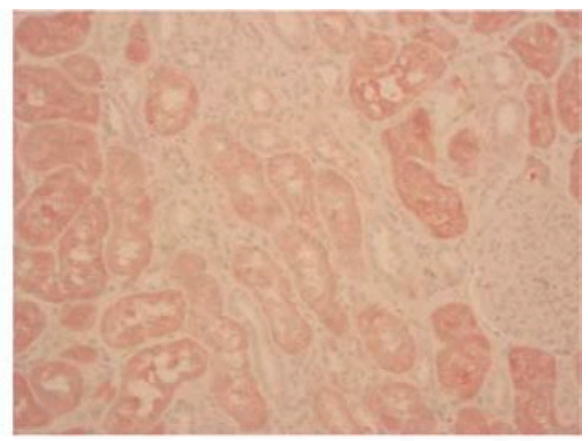

B

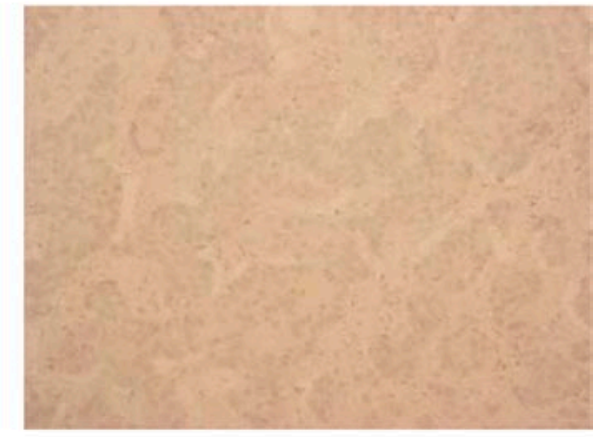

C

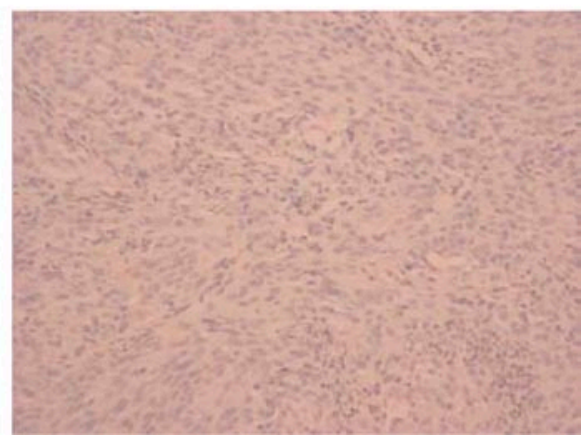

Figure 4. Immunohistochemistry for ASS in in vivo tissue sections. Typical examples of IHC analysis for ASS protein on paraffin-embedded tissues: (A) normal kidney as positive control; (B) primary hepatocellular carcinoma; (C) primary melanoma.

constitutive ASS expression were indeed resistant to ADI treatment. In our series, cells showing the capability of inducing the expression of ASS after ADI treatment presented an increased resistance to ADI; in particular, the ADI-driven inhibition of proliferation was significantly affected in a consistent fraction $(11 / 25 ; 44 \%)$ of melanoma cell lines. Conversely, no role for OTC protein on sensitivity to ADI was observed, since expression of such an enzyme was present either before or after the ADI treatment in all cell lines. This latter finding is further evidence of the difference in arginine auxotrophy between human melanomas and hepatocellular carcinomas; indeed, most of the HCC cells seems to be quite unable to express OTC (which may thus act as a key enzyme into the metabolic pathway producing intracellular levels of arginine in this type of tumour) $(7,8)$.

All in vivo melanoma and hepatocellular carcinoma tissue samples from our series were negative for ASS expression, as detected by IHC analysis. Unfortunately, only a small fraction of tissues (5 melanomas and 6 hepatocellular carcinomas) from patients previously evaluated for clinical response to ADI treatment [as documented in previous reports $(14,15)]$ 
were included in the present study; among them, a partial response was observed in 1/5 (20\%) MM patients and 1/6 (17\%) HCC patients. Although the amount of such cases is very limited, it is noticeable that the absence of ASS expression in primary tumours did not act as a full predictor of the clinical responsiveness to ADI treatment in our series [putting together the analyzed patients, all eleven cases presented lack of tissue staining for ASS protein whereas only two of them (18\%) were found to achieve an objective clinical response to ADI therapy]. In light of our in vitro findings, one could speculate that additional clues for a better assessment of the patients' responsiveness to the ADI treatment may be provided by IHC-based evaluations of the ASS expression levels on tissue sections from biopsies obtained after the beginning of the therapy (though, this implies the development of more complex trials, with several ethical aspects to be satisfied). In our case, the absence of available tissue biopsies after ADI treatment within the same series of patients did not allow to fully assess whether the low prevalence of clinical responses in such patients could in some way correlate with a putative induction of the ASS protein expression at somatic level.

Finally, it appears that targeting a single component within the multiple signaling pathways involved in the development and progression of human cancers is unlikely to yield significant antitumour responses. Therefore, further clarification of the main mechanisms involved in controlling the cancer cell growth could permit to select the subsets of patients who would be expected more likely to respond to any specific targeted treatment. In general, our efforts should be focused on avoiding that target-oriented therapies in patients carrying specific molecular alterations achieve different clinical outcomes due to the coexistence of additional alterations in alternative pathways. Correlation between in vitro and in vivo studies represents the way to evaluate the role of such novel therapies against cancer.

In conclusion, sensitivity to ADI treatment in melanoma seems to be significantly correlated with the capability of cells to express ASS either constitutively at basal level (inducing maximal resistance to the drug) or after the treatment (increasing resistance to ADI).

\section{Acknowledgements}

A special thanks to Drs Stefania D'atri and Elena Pagani, for providing most of the melanoma cell lines. Authors are grateful to patients for their important contribution to this study. Work was supported by Polaris Group (San Diego, CA, USA) (F.I.). Italian Ministry of Health Progetto Ricerca Finalizzata, Sardinia Regional Government (Regione Autonoma della Sardegna), and Associazione UMANA Onlus. Polaris Group donated the study drug.

\section{References}

1. Morris SM Jr: Regulation of enzymes of the urea cycle and arginine metabolism. Annu Rev Nutr 22: 87-105, 2002.

2. Wu G and Morris SM Jr: Arginine metabolism: nitric oxide and beyond. Biochem J 336: 1-17, 1998.

3. Tapiero H, Mathe G, Couvreur P and Tew KD: Arginine. Biomed Pharmacother 56: 439-445, 2002.

4. Husson A, Brasse-Lagnel C, Fairand A, Renouf S and Lavoinne A: Argininosuccinate synthetase from the urea cycle to the citrullineNO cycle. Eur J Biochem 270: 1887-1899, 2003.
5. Delage B, Fennell DA, Nicholson L, McNeish I, Lemoine NR, Crook T and Szlosarek PW: Arginine deprivation and argininosuccinate synthetase expression in the treatment of cancer. Int J Cancer 126: 2762-2772, 2010

6. Savaraj N, You M, Wu C, Wangpaichitr M, Kuo MT and Feun LG: Arginine deprivation, autophagy, apoptosis (AAA) for the treatment of melanoma. Curr Mol Med 10: 405-412, 2010.

7. Cheng PN, Lam TL, Lam WM, Tsui SM, Cheng AW, Lo WH and Leung YC: Pegylated recombinant human arginase (rhArg-peg $5,000 \mathrm{mw}$ ) inhibits the in vitro and in vivo proliferation of human hepatocellular carcinoma through arginine depletion. Cancer Res 67: 309-317, 2007.

8. Lam TL, Wong GK, Chong HC, Cheng PN, Choi SC, Chow TL, Kwok SY, Poon RT, Wheatley DN, Lo WH and Leung YC: Recombinant human arginase inhibits proliferation of human hepatocellular carcinoma by inducing cell cycle arrest. Cancer Lett 277: 91-100, 2009.

9. Sugimura K, Ohno T, Kusuyama T and Azuma I: High sensitivity of human melanoma cell lines to the growth inhibitory activity of mycoplasmal arginine deiminase in vitro. Melanoma Res 2: 191-196, 1992.

10. Gong H, Zolzer F, von Recklinghausen G, Rössler J, Breit S, Havers W, Fotsis T and Schweigerer L: Arginine deiminase inhibits cell proliferation by arresting cell cycle and inducing apoptosis. Biochem Biophys Res Commun 261: 10-14, 1999.

11. Wheatley DN: Controlling cancer by restricting arginine availability: Arginine-catabolizing enzymes as anticancer agents. Anticancer Drugs 15: 825-833, 2004.

12. Ensor CM, Holtsberg FW, Bomalaski JS and Clark MA: Pegylated arginine deiminase (ADI-SS PEG 20,000 mw) inhibits human melanomas and hepatocellular carcinomas in vitro and in vivo. Cancer Res 62: 5443-5450, 2002.

13. Feun L and Savaraj N: Pegylated arginine deiminase: a novel anticancer enzyme agent. Expert Opin Investig Drugs 15: 815-822, 2006.

14. Izzo F, Marra P, Beneduce G, Castello G, Vallone P, De Rosa V, Cremona F, Ensor CM, Holtsberg FW, Bomalaski JS, Clark MA, $\mathrm{Ng} \mathrm{C}$ and Curley SA: Pegylated arginine deiminase treatment of patients with unresectable hepatocellular carcinoma: results from phase I/II studies. J Clin Oncol 22: 1815-1822, 2004.

15. Ascierto PA, Scala S, Castello G, Daponte A, Simeone E, Ottaiano A, Beneduce G, De Rosa V, Izzo F, Melucci MT, Ensor CM, Prestayko AW, Holtsberg FW, Bomalaski JS, Clark MA, Savaraj N, Feun LG and Logan TF: Pegylated arginine deiminase treatment of patients with metastatic melanoma: results from phase I and II studies. J Clin Oncol 23: 7660-7668, 2005.

16. Izzo F, Montella M, Orlando AP, Nasti G, Beneduce G, Castello G, Cremona F, Ensor CM, Holtzberg FW, Bomalaski JS, Clark MA, Curley SA, Orlando R, Scordino F and Korba BE: Pegylated arginine deiminase lowers hepatitis $\mathrm{C}$ viral titers and inhibits nitric oxide synthesis. J Gastroenterol Hepatol 22: 86-91, 2007.

17. Dillon BJ, Prieto VG, Curley SA, Ensor CM, Holtsberg FW, Bomalaski JS and Clark MA: Incidence and distribution of argininosuccinate synthetase deficiency in human cancers: a method for identifying cancers sensitive to arginine deprivation. Cancer 100: 826-833, 2004.

18. Casula C, Muggiano A, Cossu A, Budroni M, Caracò C, Ascierto PA, Pagani E, Stanganelli I, Canzanella S, Sini MC, Palomba G, The Italian Melanoma Intergroup (IMI) and Palmieri G: Role of key-regulator genes in melanoma susceptibility and pathogenesis among patients from South Italy. BMC Cancer 9: 352, 2009.

19. Pisano M, Loi M, Mura ME, Tilocca MG, Palmieri G, Fabbri D, Dettori MA, Delogu G, Pagnan G, Ponzoni M and Rozzo C: Antiproliferative and pro-apoptotic activity of eugenol-related biphenyls on malignant melanoma cells. Molecular Cancer 6: 8, 2007.

20. Pisano M, Pagnan G, Dettori MA, Cossu S, Caffa I, Sassu I, Emionite L, Fabbri D, Cilli M, Pastorino F, Palmieri G, Delogu G, Ponzoni $\mathrm{M}$ and Rozzo C: Enhanced anti-tumor activity of a new curcumin-related compound against melanoma and neuroblastoma cells. Mol Cancer 9: 137, 2010.

21. Kueng W, Silber E and Eppenberger U: Quantification of cells cultured on 96-well plates. Anal Biochem 182: 16-19, 1989.

22. Sini MC, Manca A, Cossu A, Budroni M, Botti G, Ascierto PA, Cremona F, Muggiano A, D'Atri S, Casula M, Baldinu P, Palomba G, Lissia A, Tanda F and Palmieri G: Molecular alterations at chromosome 9p21 in melanocytic nevi and melanoma. Br J Dermatol 158: 243-250, 2008. 
23. Agarwala SS and O'Day SJ: Current and future adjuvant immunotherapies for melanoma: Blockade of cytotoxic T-lymphocyte antigen-4 as a novel approach. Cancer Treat Rev 37: 133-142, 2010.

24. Flaherty KT and McArthur G: BRAF, a target in melanoma: implications for solid tumor drug development. Cancer 116 4902-4913, 2010.

25. Glazer ES, Piccirillo M, Albino V, Di Giacomo R, Palaia R, Mastro AA, Beneduce G, Castello G, De Rosa V, Petrillo A, Ascierto PA, Curley SA and Izzo F: Phase II study of pegylated arginine deiminase for nonresectable and metastatic hepatocellular carcinoma. J Clin Oncol 28: 2220-2226, 2010.

26. Summar ML: Urea cycle disorders overview. In: Pagon RA, Bird TC, Dolan CR, Stephens K (eds). Gene Reviews [Internet]. Seattle: University of Washington, Seattle; 1993-2003 Apr 29 [updated 2005 Aug 11].
27. You M, Savaraj N, Wangpaichitr M, Wu C, Kuo MT, VaronaSantos J, Nguyen DM and Feun L: The combination of ADI-PEG20 and TRAIL effectively increases cell death in melanoma cell lines. Biochem Biophys Res Commun 394: 760-766, 2010

28. Bowles TL, Kim R, Galante J, Parsons CM, Virudachalam S, Kung HJ and Bold RJ: Pancreatic cancer cell lines deficient in argininosuccinate synthetase are sensitive to arginine deprivation by arginine deiminase. Int J Cancer 123: 1950-1955, 2008.

29. Yoon CY, Shim YJ, Kim EH, Lee JH, Won NH, Kim JH, Park IS, Yoon DK and Min BH: Renal cell carcinoma does not express arginino-succinate synthetase and is highly sensitive to arginine deprivation via arginine deiminase. Int J Cancer 120: 897-905, 2007. 